THE acquired immunodeficiency syndrome (AIDS) is a clinically multifaceted disease induced by infection with the human immunodeficiency virus (HIV). HIV infection results in a complex pattern of immunologic alterations that leads to the development of AIDS in the majority of HIV seropositive (HIV+) individuals. The reduction in CD4 $T$ lymphocyte counts is the hallmark of HIV infection; nevertheless, long before the reduction in CD4 counts reaches critical levels, a series of profound and complex defects that impair the function of CD4 T lymphocytes can be detected. Thus, HIV infection is characterized by quantitative and qualitative defects affecting CD4 $T$ lymphocytes. It was suggested recently that programmed cell death (PCD) is an important mechanism leading to CD4 depletion in HIV infection, and that susceptibility of peripheral lymphocytes to PCD is differentially regulated by diverse cytokines. Thus, type 1 cytokines would protect CD4 lymphocytes against PCD, whereas type 2 cytokines would not protect against, and could augment, PCD. We suggest that the qualitative alterations of the immune response provoke the CD4 depletion characteristic of HIV disease via type 2 cytokinemediated augmentation of PCD, and are therefore ultimately responsible for the progression of HIV infection. Finally, we summarize recent data showing that three correlates of disease progression: emergence of HIV strains with syncitium-inducing ability (SI), type 1-to-type 2 cytokine shift, and CD4 depletion, are significantly associated, suggesting a complex interconnected virologic-immunologic pathogenesis of HIV infection.

Key words: Breakdown, Cytokine network, HIV.

\section{The breakdown of the cytokine network subsequent to human immunodeficiency virus infection}

\author{
M. Clerici, ${ }^{1, C A}$ M. L. Villa, ${ }^{1}$ D. Trabattoni ${ }^{1}$ and \\ G. M. Shearer ${ }^{2}$
}

${ }^{1}$ Cattedra di Immunologia, Università di Milano, Italy and ${ }^{2}$ Experimental Immunology Branch, National Cancer Institute, National Institutes of Health, Bethesda, MD 20892, USA

${ }^{\mathrm{CA}}$ Corresponding Author

\section{Defective interleukin-2 production as the hallmark of qualitative lymphocyte defects in HIV infection}

Early and complex $\mathrm{T}$ helper (Th) cells defects have been described in HIV infected individuals. ${ }^{1-6}$ We have analysed the qualitative defects of HIV infection by examining in vitro antigenand mitogen-stimulated interleukin (IL)-2 production by PBMC of $\mathrm{HIV}+$ individuals. PBMC were stimulated in vitro with recall antigens (influenza virus, tetanus toxoid, or HIV peptides); HLA alloantigens (ALLO); or phytohaemagglutinin (PHA). ${ }^{5}$ These stimuli were chosen because they activate different Th-antigen presenting cell (APC) pathways, ${ }^{7}$ allowing for a more complete evaluation of the immune system. Thus, recall antigens are exclusively presented by self-APC to autologous CD4; HLA alloantigens can be presented by self-APC to autologous CD4 or they can be directly recognized by autologous CD4 and CD8 T lymphocytes on the surface of allogeneic APC; whereas PHA stimulation of T lymphocytes is only marginally dependent on processation and presentation by APC (see Table 1). ${ }^{7}$

The stimulation of PBMC with this panel of antigens allowed us to recognize that only a minority $(\approx 40 \%)$ of $\mathrm{HIV}+$ asymptomatic patients can respond by IL- 2 production to recall, ALLO and PHA. ${ }^{5}$ Thus, a complex pattern of defects in IL-2 production was observed in the majority of $\mathrm{HIV}+$, asymptomatic individuals. Indeed, approximately $40 \%$ of these individuals showed a selective defect in IL-2 production in response to recall antigens, whereas $\approx 10 \%$ of them could only respond to PHA, or could not produce IL-2 in response to any stimulation $(\approx 10 \%) .^{5}$ Because all these patients were in the same clinical stage (Walter-Reed stage 1), and 
Table 1. Pathways of $\mathrm{T}$ helper cell activation

\begin{tabular}{lccc}
\hline Antigen & $\begin{array}{c}\text { T helper } \\
\text { cell }\end{array}$ & $\begin{array}{c}\text { Antigen } \\
\text { presenting cell }\end{array}$ & $\begin{array}{c}\text { IL-2 } \\
\text { production }\end{array}$ \\
\hline Recall antigens & CD4+ & self APC & ++ \\
HLA alloantigens & CD4+ & self APC & ++ \\
& CD4+ & allo APC & +++ \\
& CD8+ & allo APC & ++ \\
\hline
\end{tabular}

PHA-stimulated IL-2 production is marginally dependent on processation and presentation by APC.

had comparable CD 4 counts ( $>400 \mathrm{mmc}$ ) the observed functional defects were not secondary to a decrease in CD4 counts. ${ }^{5}$ These experiments allowed us to conclude that: (1) defective ability to produce IL-2 can be detected even in the earlier, asymptomatic phases of HIV infection; and (2) these defects are not secondary to either a decrease in $\mathrm{CD} 4$ counts or a clinical progression in HIV infection. Similar analyses in vertically transmitted paediatric HIV infection showed that: (1) defective IL-2 production is observed also in the majority of $\mathrm{HIV}+$ paediatric patients; ${ }^{8}$ and (2) defective in vitro antigen- and mitogen-stimulated IL-2 production is associated in paediatric HIV disease with an augmented incidence of opportunistic and bacterial infections. ${ }^{8}$ In the attempt to analyse whether the defective element is the $\mathrm{T}$ lymphocyte or the antigen presenting cell, we performed experiments in which cells of HIV-discordant monozygotic twins were matched. The results repeatedly indicated the absence of defects in the ability of HIV + APC to process and present antigens. ${ }^{9,10}$

We subsequently verified whether defects in IL-2 production could be reverted by treatment with antiretroviral drugs. Thus, we measured in vitro stimulated $\mathrm{T}$ lymphocyte proliferation and IL-2 production in two cohorts of HIV + adults and one cohort of paediatric patients, treated with zidovudine, SCD4-IgG or ddI respectively. We observed that all three compounds were capable of temporarily restoring IL-2 production independently of any variation in $\mathrm{CD} 4$ counts. ${ }^{11-13}$ That this is not an aspecific effect of all antiretroviral drugs was shown by a fourth compound, which was not able to restore $T$ lymphocyte proliferation or IL-2 production (M. Clerici et al., unpublished observations). Additionally, the in vitro restoration of IL-2 production by antigen- or mitogen-stimulated peripheral blood mononuclear cells provoked by ddI was associated in paediatric HIV infection with a significant reduction of opportunistic infections during clinical follow-up. ${ }^{2}$ Again, the positive changes in clinical parameters was associated with improved $\mathrm{T}$ lymphocyte function, but independent of variations in $\mathrm{CD} 4$ counts.

\section{The type 1/type 2 hypothesis of HIV infection}

In the late 1980s it was shown by different investigators that murine $T$ helper cells can be functionally distinguished in two subsets which are differentially specialized in furnishing preferential help to cytotoxic T lymphocytes (CTL) or B lymphocytes. ${ }^{14-17}$ These two sub-populations, named $\mathrm{T}$ helper 1 (TH1) and $\mathrm{T}$ helper 2 (TH2), respectively, were subsequently described in humans by Romagnani. ${ }^{18,19}$ It was suggested recently that some phenotypic markers may allow us to differentiate TH1 and TH2 lymphocytes. Thus, it was reported that TH2 lymphocytes may express higher quantities of $\mathrm{CD} 30,{ }^{20}$ as well as of a particular isoform of BB-7 (BB-7.2). A third group has observed that $\mathrm{CD} 4+\mathrm{CD} 7+\mathrm{T}$ lymphocytes preferentially secrete TH1 cytokines, whereas $\mathrm{CD} 4+\mathrm{CD} 7-\mathrm{T}$ lymphocytes preferentially produce $\mathrm{TH} 2$ cytokines. ${ }^{21}$ Nevertheless, no marker has yet been identified that exclusively clusters on $\mathrm{TH} 1$ or $\mathrm{TH} 2$, and the definition of TH1 and TH2 lymphocytes is still essentially based on the different cytokines that are produced by these cells. Thus, TH1 responses are characterized by secretion of interferon (IFN)- $\gamma$ and IL-2 and subsequent promotion of cell mediated immunity (CMI), whereas $\mathrm{TH} 2$ responses are characterized by secretion of IL- 4 and IL-5, with subsequent activation of humoral immunity and generation of antibodies. Interestingly, TH1 and TH2 are cross-regulating as IFN- $\gamma$ suppresses the activation of TH2 lymphocytes, whereas IL-4 suppresses the production of TH1 cytokines.

IL-2 is a prototypical product of TH1 lymphocytes, and IL-2 production can be down-regulated by TH2 cytokines (classically IL-4). Thus, we began exploring the possibility that the defective IL-2 production observed in HIV + asymptomatic infection could be accompanied by augmented IL-4 production. We decided to analyse cytokine production by whole PBMC and not by $\mathrm{CD} 4+\mathrm{T}$ cell clones because we believe cytokine production by whole PBMC to be a more important approximation to the in vivo situation. ${ }^{22,23}$ In fact, even if $\mathrm{T}$ cell clones are an important experimental tool, we were concerned about the artefacts present in the cloning methodology. Our concerns about clones can be summarised as follows: (1) Th cell cloning results in the loss (during the cloning process) of important, non-T accessory cells that produce cytokines with immunoregulatory properties, (2) cloning may 
Table 2. TH1 and TH2 cytokines are clonally defined; type 1 and type 2 cytokines are functionally defined

\begin{tabular}{|c|c|}
\hline TH1 cytokines & TH2 cytokines \\
\hline $\begin{array}{l}\text { Interferon } \gamma \\
\text { Interleukin-2 }\end{array}$ & $\begin{array}{l}\text { Interleukin-4 } \\
\text { Interleukin-5 }\end{array}$ \\
\hline Type 1 cytokines & Type 2 cytokines \\
\hline $\begin{array}{l}\text { Interferon } \gamma \\
\text { Interleukin-2 } \\
\text { Interleukin-12 } \\
\text { Interleukin-15 (?) }\end{array}$ & $\begin{array}{l}\text { Interleukin-4 } \\
\text { Interleukin-5 } \\
\text { Interleukin-6 } \\
\text { Interleukin-10 } \\
\text { Interleukin-13 (?) }\end{array}$ \\
\hline
\end{tabular}

select for populations of $T$ cells, as the techniques involve the selection and expansion of cells in relatively high concentrations of IL-2; and (3) the investigation of PBMC tests for the effects of cytokines produced by multiple cell types on Th cell function, and includes both autocrine and paracrine regulation whereas in cloned $T$ cell tests for the cytokines produced by these clones is limited to autocrine regulation. Because our observations were based on cytokine production by all the cells circulating in the peripheral blood and not on clonal isolation, we decided to identify the cytokine patterns observed as type 1 (mainly CMI-inducing), and type 2 (mainly humoral immunity-inducing). ${ }^{22,23}$ Because we defined cytokines on a functional basis, we could enlarge the group of type 1 cytokines to include IL-12 and, probably, IL-15 (all cytokines that mainly stimulate CMI, but are not mainly or exclusively produced by clones of CD4 $+\mathrm{T}$ lymphocytes) in addition to IL- 2 and IFN- $\gamma$. Similarly, IL-6, IL-10 and probably IL-13 were considered to be type 2 cytokines even if they are produced by cells other than $\mathrm{CD} 4+\mathrm{T}$ lymphocytes, as their main effect is that of stimulating $B$ cell activity and antibody generation (see Table 2).

To measure IL-4, we stimulated PBMC of $\mathrm{HIV}+$ asymptomatic donors in vitro with PHA for 48 to $72 \mathrm{~h}$, as suggested by kinetic studies, and we evaluated the amount of IL- 4 present in the supernatants using a cell line (a kind gift of Dr William Paul, NIAID, NIH) whose growth is dependent on IL-4. (To simplify the assay, we are now measuring IL-4 using commercially available ELISA kits.) To analyse the production of IL- 4 at the molecular level, we also quantified (in collaboration with Dr Thomas Wynn, NIAID, NIH) the expression of IL- 4 mRNA in the PBMC of the same patients. We observed that IL-4 production was greatly augmented in PHA-stimulated supernatants of $\mathrm{HIV}+$ individuals as compared to HIV - controls, and that the increased IL-4 production was most likely to be observed in the subset of HIV + asymptomatic patients showing defective IL-2 generation in response to recall antigens. ${ }^{24}$ Similarly, IL- 4 mRNA was detected in PHA stimulated PBMC of HIV + individuals, but not in unstimulated PBMC of the same individuals, or in HIV - controls. ${ }^{24}$ Even more important, IL-4 neutralizing antibodies were capable to restore in vitro antigen-stimulated proliferation and IL-2 production in the majority of patients secreting high amounts of IL-4. ${ }^{24}$

Because IL-10 was described as able to suppress the secretion of type 1 cytokines and CMI even more powerfully than IL- 4 , we next decided to measure IL-10 production in HIV + asymptomatic patients. Similarly to the methods used to generate IL-4, we stimulated PBMC in vitro with PHA for $48 \mathrm{~h}$; the amount of IL-10 produced was measured using commercially available ELISA kits, and IL-10 mRNA was quantified using PCR methods. We observed that IL-10 production was augmented in $\mathrm{HIV}+$ asymptomatic patients showing defective IL-2 production, and that the patients with the most severe defective IL-2 production (i.e. inability to generate IL- 2 even in response to PHA) generated the highest quantities of IL-10. ${ }^{25}$ By analogy to what was observed for neutralizing antibodies to IL-4, in vitro antigen-stimulated proliferation and IL-2 production could be restored in the majority of these patients by neutralizing antibodies to $\mathrm{IL}-10{ }^{25}$ Similarly, we could restore in vitro antigen-stimulated proliferation and IL-2 production, as well as mitogen-stimulated IFN- $\gamma$ production, by IL-12, a prototypical type- 1 cytokine described by Chehimi et al. as defective, even in the earlier phases of HIV infection. ${ }^{27}$ Thus, we proposed that HIV infection is associated with the progressive impairment of type 1 cytokine production, and the progressive augmentation of type 2 cytokine secretion. ${ }^{22,23}$ It is important to underline that these events are observed in the asymptomatic phase of HIV infection, before the development of full blown disease. These data, confirmed by numerous other authors, ${ }^{28-37}$ are the experimental basis of the type- $1 /$ type-2 hypothesis of HIV infection.

Because cytokine secretion is associated with a quantity of diverse biological effects which are readily measurable, we suggest that the list of these effects, which are frequently observed in HIV + patients and are presented in Table 3, strongly support the hypothesis of a profound cytokine imbalance in HIV infection. Thus, the impairment of delayed type hypersensitivity reaction is secondary to defective IFN- $\gamma, \mathrm{IL}-2$ and IL12 production, whereas hyper-IgE is secondary to the augmented production of IL-4, and hypereosinophilia is secondary to the augmented pro- 
Table 3. Unfavourable prognostic signs in HIV infection

Decreased production of type 1 cytokines (IFN- $\gamma$, IL-2, IL-12)

Increased production of type 2 cytokines (IL-4, IL-5, IL-6, IL-10)

Reduced delayed type hypersensitivity (DTH) reactions

IL-4-driven hyper-lgE

IL-5-driven hypereosinophilia

duction of IL-5. All these parameters are predictors of poor prognosis in HIV infection. ${ }^{38-46}$ Interestingly, it has recently become evident that defective in vitro antigen- and mitogen-stimulated IL-2 production is predictive for subsequent reduction in CD4 counts, the time to acquired immunodeficiency syndrome (AIDS), and time to death. ${ }^{47}$

\section{Different patterns of disease progression in HIV infection}

Higher CD4 counts, better preserved IL-2 secretion, and the absence of the clinical signs of type 1/type 2 cytokine imbalance listed in Table 3 are associated with a lack of progression of HIV infection. It has recently become evident that, although the vast majority of $\mathrm{HIV}+$ individuals progress to AIDS, a minority of HIV+ patients exists that does not develop AIDs or show a critical reduction in CD4 $\mathrm{T}$ cells, despite long-lasting infection with HIV. ${ }^{48}$ These patients have recently been defined long-term non-progressors (LTNP). Different groups have focused on diverse aspects of this phenomenon, the solution of which holds the possible key to a cure for AIDS. Two biological interpretations can be offered in the attempt to explain long-lasting HIV infection without AIDS. Thus, these patients may have been infected by a defective, less pathogenic HIV variant, or these patients may have a stronger immune response, capable of keeping HIV under control. More likely, a strong immune response is preventing HIV from becoming frankly virulent in these individuals. In support of this hypothesis are the findings by $\mathrm{Ho}$ and colleagues, and Fauci and colleagues indicating that strong HIV-specific CTL were observed in two groups of LTNP. ${ }^{49,50}$ Additionally, it was recently shown that: (1) preserved $\mathrm{T}$ cell function correlates with stable CD4 counts; ${ }^{51}$ (2) disease-free survival correlates with gag-specific cytotoxic T lymphocyte activity; ${ }^{52,53}$ and (3) HIV infected chimpanzees become seropositive but do not progress toward AIDS. ${ }^{54}$ Finally, it has recently been verified that neither a type 1-to-type 2 cytokine shift nor programmed cell death are present in HIV + chimpanzees. ${ }^{55,56}$
We have recently analysed (in collaboration with the Clinica delle Malattie Infettive, Università di Milano) cytokine production in a group of LTNP, and compared the cytokine profile with that observed in a group of patients with progressive HIV infection. As we expected, a strong type 1/weak type 2 cytokine profile was observed in the LTNP, whereas a symmetrically opposite weak type 1 /strong type 2 cytokine profile was observed in patients with progressive HIV infection. ${ }^{57}$ Interestingly, a significantly increased percentage of $\mathrm{CD} 4+/ \mathrm{CD} 7-\mathrm{T}$ lymphocytes (as remembered above, $\mathrm{CD} 4+/ \mathrm{CD} 7-\mathrm{T}$ lymphocytes predominantly secrete type 2 cytokines) was observed in the individuals with progressive HIV infection, but not in the LTNP. ${ }^{57}$

We have performed (in collaboration with the Cattedra di Pediatria IV, Università di Milano) a second study in a cohort of vertically infected children with different patterns of disease progression. In fact, HIV vertical infection follows a bimodal pattern according to which $20 \%$ of vertically infected children develop AIDS and eventually die within the first year of life, whereas the remainder develop AIDS at a constant rate per year, reaching the median at about 5 years after birth. $^{58}$ We have thus studied a group of vertically infected HIV + children who did not develop AIDS within the first year of life, and we identified two subsets of children of comparable age, the first one of which was asymptomatic, while the second one showed severe signs of HIV disease. The results indicated that, despite the presence of severe defects in type 1 cytokine production in both groups of children, a greatly increased type 2 cytokine secretion was characteristic of the symptomatic, but not of the asymptomatic children. ${ }^{43}$ Interestingly, a sig. nificant association with hyper-IgE (the production of which is stimulated by IL-4 secretion) was observed in the paediatric cohort. ${ }^{43}$ Thus, we suggest that a strong type 1/weak type 2 cytokine production is associated with delayed (or absent) progression of HIV infection to AIDS.

\section{Susceptibility of T lymphocytes to programmed cell death (PCD) is differentially regulated by type 1 and type 2 cytokines}

It has been observed that PCD is increased in HIV infection, and it was thus suggested that PCD could be one of the mechanism(s) primarily responsible for $\mathrm{CD} 4$ depletion in the progression to AIDS ${ }^{59,60}$ HIV + lymphocytes undergo PCD in unstimulated conditions, and much more so when stimulated with mitogens. ${ }^{60,61}$ One of the 
major differences between HIV + and HIV - lymphocytes is that whereas only mitogen-activated HIV - lymphocytes (blasts) will undergo PCD upon a second mitogenic restimulation, even resting (unstimulated) HIV + PBMC will undergo PCD upon stimulation. Therefore, two serial in vitro stimuli are needed to induce PCD in HIV lymphocytes, whereas a single in vitro stimulation will provoke PCD in HIV + lymphocytes, suggesting that in HIV infection lymphocytes are preactivated in vivo to undergo PCD upon in vitro restimulation. ${ }^{60,61}$

Mitogenic stimulation will activate $\mathrm{CD} 4$ and CD8 lymphocytes via $\mathrm{T}$ cell receptor-mediated stimulation, inducing PCD in both subsets of $T$ lymphocytes. It was recently observed that PCD is differentially regulated by type 1 and type 2 cytokines. ${ }^{61}$ Thus, PCD was prevented in vitro by IFN- $\gamma$, IL- 2 and IL-12 ${ }^{61}$ whereas PCD was not prevented, or was augmented, by IL- 4 and IL-10. ${ }^{61}$ Even more relevant was the observation that PCD could be prevented by neutralizing antibodies to type 2 cytokines, but could not be prevented, or was even raised by neutralization of type 1 cytokines. $^{62}$ We have recently observed that the selective stimulation of $\mathrm{CD} 4+$ lymphocytes by recall antigens will induce $P C D$ exclusively in the CD4 subset, a situation that more closely resembles that observed in vivo. Even in this situation, PCD was oppositely modulated by type 1 and type 2 cytokines, or by the neutralization of type 1 or type 2 cytokines. Additionally, we verified that PCD is effected by lymphotoxin, and that lymphotoxin is responsible for a soluble-factor mediated amplifying loop which causes PCD in innocent-bystander lymphocytes. Finally, the PCD-inducing effect of lymphotoxin is differentially influenced by type 1 and type 2 cytokines (M. Clerici et al., submitted). We suggest that the impaired production of type 1 cytokines and the augmented generation of type 2 cytokines characteristic of HIV infection results in the destruction of CD4 lymphocytes, which is increased by type 2 cytokines and mediated by lymphotoxin. Thus, antigen stimulation of HIV + lymphocytes in the presence of abnormally low concentrations of IFN- $\gamma, \mathrm{IL}-2$ and IL-12, and of abnormally elevated concentrations of IL- 4 and IL-10 results in the induction of PCD, instead of the induction of $\mathrm{T}$ cell proliferation.

\section{Virologic and immunologic correlates of poor prognosis are associated}

Finally, it was suggested that the development of AIDS is secondary to the emergence of an HIV phenotype with a rapid/high replication rate, a tropism for different cell lines, and the capacity to induce the formation of syncytia in vitro. ${ }^{62-67}$ To verify whether the isolation of syncytiuminducing HIV is correlated with the type 1-to-type 2 cytokine shift, we have analysed virologic and immunologic parameters in two groups of HIV vertically infected children of comparable age who have or have not progressed to AIDS. We observed that progression to AIDS in paediatric HIV infection is associated with isolation of HIV SI variants and increased production of the type 2 cytokines IL-4 and IL-10. Additionally, we observed that these two parameters are statistically associated and that extensive CD4 loss is associated both with the isolation of SI variants and increased IL-4 production (M. Clerici et al., submitted). These recent data indicate that the virologic and immunologic parameters characteristic of advanced HIV infection are strictly associated, and strongly support a virologicimmunologic pathogenesis leading the appearance of AIDS.

\section{Conclusions}

We suggest that the complex qualitative alterations observed in HIV infection are responsible for the progression of HIV disease to AIDS, and that the dramatic reduction of $\mathrm{CD} 4 \mathrm{~T}$ lymphocytes which is the hallmark of this disease is mainly secondary to phenomena of PCD that is increased by a type 1 /type 2 cytokine imbalance. Thus, we suggest that every therapeutic approach to HIV infection should consider the necessity to restore the normal functionality of the immune system. These approaches could at least theoretically be based on the utilization of: (1) type 1 cytokines; (2) antibodies neutralizing type 2 cytokines; or (3) pharmacological compounds aimed at the selective stimulation of type 1 cytokine secretion and subsequent augmentation of CMI. It is important to notice that the results of a first clinical trial based on the utilization of IL-2 have shown significant improvement in CD4 counts (possibly via the prevention of IL-2-induced PCD). ${ }^{68}$ Thus, we strongly favour approaches based on the restoration of normal cytokine production in the therapy for HIV infection, as we believe that a strong CMI is associated with better prognosis, and will ultimately be more capable of controlling HIV replication and disease progression.

ACKNOWLEDGEMENTS. This work was supported by grants Istituto Superiore di Sanità n. 9204-31 and 9304-40. 


\section{References}

1. Lane HC, Depper JM, Greene WC et al. Qualitative analysis of immune function in patients with the acquired immunodeficiency syndrome: evidence for a selective defect in soluble antigens recognition. $N$ Eng J Med 1985; 313: 79-84.

2. Smolen JS, Bettleheim P, Koller U et al. Deficiency of the autologous mixed lymphocyte reaction in patients with classic hemophilia treated with communical Factor VIII concentrate: correlation with $\mathrm{T}$ cell subset distribution, antibodies to lymphadenopathy-associated or human $\mathrm{T}$ lymphotropic virus, and analysis of the cellular basis of the deficiency. J Clin Invest 1985; 75: 1828-1834.

3. Giorgi JV, Fahey JL, Smith DC et al. Early effects of HIV on CD4 lymphocytes in vivo. J Immunol 1987; 138: 3725-3730.

4. Miedema F, Petit AJ, Terpstra FG et al. Immunological abnormalities in human immunodeficiency virus (HIV)-infected asymptomatic homosexual men. HIV affects the immune system before CD4 + T helper cell depletion occurs. J Clin Invest 1988; 82: 1908-1916

5. Clerici M, Stocks NI, Zajac RA et al. Detection of three distinct patterns of $\mathrm{T}$ helper cell dysfunction in asymptomatic, human immunodeficiency virus-seropositive patients. Independence of $\mathrm{CD} 4+$ cell numbers and clinical staging. J Clin Invest 1989; 84: 1892-1899.

6. Shearer GM, Clerici M. Early T helper defects in HIV infection. AIDS 1991; 5: 245-254.

7. Via CS, Tsokos GC, Stocks NI, Clerici M, Shearer GM. Human in vitro allogeneic responses: demonstration of three pathways of $\mathrm{T}$ helper cell activation. J Immunol 1991; 144: 2524-2528.

8. Roilides E, Clerici M, DePalma L, Rubin M, Pizzo PA, Shearer GM. T helper cell responses in children infected with human immunodeficiency virus type 1. J Pediatrics 1991; 118: 724-730.

9. Clerici M, Stocks NI, Zajac RA, Boswell RN, Shearer GM. Accessory cell function in asymptomatic, human immunodeficiency virus infected patients. Clin Immunol Immunopatbol 1990; 54: 168-173.

10. Blauvelt A, Clerici M, Lucey DL et al. Functional studies of epidermal Lan gherans cells and blood monocytes in human immunodeficiency virus infected individuals. J Immunol 1995; 154: 3506-3515.

11. Clerici M, Landay A, Kessler H, Venzon DV, Lucey DL, Shearer GM Reconstitution of $\mathrm{T}$ helper cell function following zidovudine therapy in HIV infected patients J Infect Dis 1992; 166: 723-730.

12. Clerici $\mathrm{M}$, Roilides $\mathrm{E}$, Butler $\mathrm{KM}$ et al. Changes in $\mathrm{T}$ helper cell function in human immunodeficiency virus infected children during dideoxyinosine therapy as a measure of antiretroviral activity. Blood 1992; 80: 2196-2202.

13. Clerici M, Yarchoan R, Blatt S et al. Effect of recombinant CD4-IgG on in vitro $\mathrm{T}$ helper cell function: data from a phase $\mathrm{I} / \mathrm{II}$ study on patients with the acquired immunodeficiency syndrome (AIDS). J Infect Dis 1993; 168: $1012-1016$.

14. Mosmann TR, Coffman RI. Two types of mouse T helper cell clone: implication for immune regulation. Immunol Today 1987; 8: 223-226.

15. Mosmann TR, Coffman RI. TH1 and TH2 cells: different pattern of lym phokine secretion lead to different functional properties. Annu Rev Immunol 1989; 7: 145-168.

16. Fiorentino DF, Bond MW, Mosmann TR. Two types of mouse T helper cell. IV. Th2 clones secrete a factor that inhibits cytokine production by Th1 clones. J Exp Med 1989; 170: 2081-2089.

17. Swain S. Regulation of the development of distinct subsets of $\mathrm{CD} 4+\mathrm{T}$ cells. Res Immunol 1991; 142: 14-55.

18. Del Prete GF, De Carli M, Mastromauro C et al. Purified protein derivative of Mycobacterium tuberculosis and excretory-secretory antigen(s) of Toxocara canis expand in vitro human $\mathrm{T}$ cells with stable and opposite (type 1 helper or type 2 helper) profile of cytokine production. J Clin Invest 1991; 88: 346-350.

19. Romagnani S. Human TH1 and TH2 subsets: doubt no more. Immunol Today 1991; 12: 256-257.

20. Del Prete GF, Maggi E, Pizzolo G, Romagnani S. XD30, Th2 cytokines and HIV infection: a complex and fascinating link. Immunol Today 1995; 16: $76-80$.

21. Legac $E$, Autran $B$, Merle-Beral $H$, Katlama $C$, Debre $P$ $\mathrm{CD}^{+}{ }^{+} \mathrm{CD} 7^{-} \mathrm{CD} 57^{+} \mathrm{T}$ cells: a new T-lymphocyte subset expanded during human immunodeficiency virus infection. Blood 1992; 79: 1746-1753.

22. Clerici M, Shearer GM. Is HIV associated with a TH1 $\rightarrow$ TH2 switch? Immunol Today 1993; 14: 107-111.

23. Clerici M, Shearer GM. The TH1/TH2 model of HIV infection: new insights. Immunol Today 1994; 15: 575-581.

24. Clerici M, Hakim FT, Venzon DJ et al. Changes in interleukin 2 and inter leukin 4 production in asymptomatic, HIV-seropositive individuals. J Clin Invest 1993; 91: 759-765.

25. Clerici M, Wynn TA, Berzofsky JA et al. Role of interleukin-10 (IL-10) in T helper cell dysfunction in asymptomatic individuals infected with the human immunodeficiency virus (HIV-1). J Clin Invest 1994; 93: 768-775.

26. Clerici M, Lucey DR, Pinto LA et al. Restoration of HIV-specific cell mediated immune responses by interleukin-12 in vitro. Science 1993; 262 : 1721-1724.

27. Chehimi J, Trinchieri G, Frank I et al. IL-12 deficiency in HIV-infected patients. J Exp Med 1994; 179: 1361-1366.
28. Naviskas V, Link J, Warhen B, Persson C, Link H. Increased levels of interferon-gamma (IFN-gamma), IL- 4 and transforming growth factor-beta (TGF-beta) mRNA expressing blood mononuclear cells in human HIV infection. Clin Exp Immunol 1994; 96: 59-63.

29. Meeyard L, Otto SA, Keet IPM, Van Lier RAW, Miedema F. Changes in cytokine secretion patterns of $\mathrm{CD} 4+\mathrm{T}$ cell clones in HIV infection. Blood 1994; 84: 4262-4270.

30. Benjamin D, Knobloch TJ, Dayton MA. Human B-cell interleukin-10: Bcell lines derived from patients with AIDS and Burkitt lymphoma con. stitutively secrete large quantities of interleukin-10. Blood 1992; 80: 1289-1299.

31. Akridge RE, Oyafuso LKM, Reed SG. IL-10 is induced during HIV-1 infection and is capable of decreasing viral replication in human macro phages. J Immunol 1994; 153: 5782-5788.

32. Emilie D, Fior L, Llorente A et al. Cytokines from lymphoid organs of HIV-infected patients: production and role in the immune disequilibrium of the disease and in development of B lymphomas. Immunol Rev 1994; 140: $5-35$.

33. Naviskas V, Link J, Warhen B, Persson C, Link H. Increased expression of IL-6, IL-10, TNF-alfa and perforin in blood mononuclear cells in human HIV infection. AIDS Res Hum Retrovir (in press).

34. Erard F, Wild MT, Garcia-Sanz JA, LeGros G. Switch of CD8 T cells to noncytokitic CD8-CD4 - cells that make Th2 cytokines and help B cells. Science 1993; 260: 1802-1805.

35. Barcellini W, Rizzardi GP, Borghi MO, Fain C, Lazzarin A, Meroni PL. TH1 and TH2 cytokine production by peripheral blood mononuclear cells from HIV-infected patients. AIDS 1994; 8: 757-762.

36. Miedema $\mathrm{F}$, Meyaard L, Koot $\mathrm{M}$ et al. Changing virus-host interactions in the course of HIV infection. Immunol Rev 1994; 140: 35-72.

37. Maggi E, Giudizi MG, Biagiotti $R$ et al. Th2-like CD8 + cells showing B cell helper function and reduced cytolytic activity in HIV-1 infection. $J$ Exp Med 1994; 180: 489-495.

38. Blatt SP, Hendrix CW, Butzin CA et al. Delayed type hypersensitivity skin testing predicts progression to AIDS in HIV-infected patients. Ann Int Med 1993; 119: 177-184.

39. Markowitz N, Hansen NI, Wilcosky TC et al. Tubercolin and anergy testing in HIV-seropositive and HIV-seronegative persons. Ann Int Med 1993; 119: 185-193.

40. Lucey DR, Zajac RA, Melcher GP and the USAF HIV Study Group. Serum IgE levels in 622 persons with HIV infection: IgE elevation with marked depletion of CD4 + T-cells. AIDS Res Hum Retrovir 1990; 6: 427-429.

41. Israel-Biet D, Labrousse F, Tourani J-M, Sors H, Andrieu JM, Even P. Elevation of IgE in HIV-infected subjects: A marker of poor prognosis. $J$ Allergy Clin Immunol 1993; 89: 68-75.

42. Viganò A, Crupi L, Principi N, Salvaggio A. Elevation of IgE in HIV-infected children and its correlation with the progression of the disease. $J$ Allergy Clin Immunol 1995 (in press).

43. Viganò A, Principi N, Villa ML, Trabattoni D, Crupi L, Clerici M. Immunologic characterization of children vertically infected with human immunodeficiency virus with slow or rapid progression. J Pediatrics 1995; 126: 368-374.

44. Fleury-Feith J, Van Nheieu JT, Picard C, Escudier E, Bernaudin JF. Bronchoalveolar lavage eosinophilia associated with pneumocystis carinil pneumonia in AIDS patients. Comparative study with non-AIDS patients. Chest 1992; 95: 1198-1201.

45. Smith KJ, Skelton HG, Drabick JJ, McCarthy WF, Ledsky R, Wagner KF. Hypereosinophilia secondary to immunodysregulation in patients with HIV-1 disease. Arch Dermatol 1994; 130: 119-121.

46. Caterino-de-Araujo A. HIV-1 infection and eosinophilia. Immunol Today 1994; 15: 498-499.

47. Dolan MJ, Blatt SP, Clerici M et al. A functional and phenotypic assessment of T-helper cells in HIV-1 infected patients offers independent prognostic information for survival. $J$ Infect Dis (in press).

48. Levy JA. HIV pathogenesis and long-term survival. AIDS 1993; 7: 14011410.

49. Cao Y, Qin L, Zhang L et al. Virologic and immunologic characterization of long-term survivors of HIV type 1 infection. N Eng J Med 1995; 332: 201-208.

50. Pantaleo G, Menzo S, Vaccarezza $M$ et al. Studies in subjects with long term nonprogressive HIV infection. N Eng J Med 1995; 332: 209-216.

51. Keet IPM, Krol A, Klein MR et al. Long-term asymptomatic HIV-1 infection with normal and low CD4 counts. J Infect Dis 1994; 169: 1236-1241.

52. Gotch FM, Rowland-Jones S, Nixon DF. Longitudinal studies of HIV gag specific cytotoxic $\mathrm{T}$ lymphocyte responses over time in several patients. In: Racz P, Letvin NL and Gluckman JC eds. Cytotoxic T Cells in HIV and Other Retroviral Infections. Karger: Basel 1992; 60

53. Riviere Y, McChesney M, Porrot F et al. Role of HIV specific cytotoxic effector cells in disease progression. XI International Conference on AIDS. Berlin, Germany, 6-11 June 1993 [Abstract WS B 03-4].

54. Nara P, Hatch W, Kessler J, Kelliher J, Carter S. The biology of HIV-1 IIIB infection in the chimpanzee: in vivo and in vitro correlations. J Med Primatol 1989; 18: 343-355.

55. Heeney J, Jonker R, Koornstra W et al. The resistance of HIV-infected chimpanzees to progression to AIDS correlates with absence of HIV. related T cell dysfunction. J Med Primatol 1993; 22: 194-200.

56. Gougeon ML, Garcia S, Heeney J et al. Programmed cell death in AIDS related HIV and SIV infections. AIDS Res Hum Retrovir 1993; 9: 553-560. 
57. Clerici M, Meroni L, Balotta C et al. Cytokine production and phenotypic analyses of HIV seropositive long term non progressors patients. $J$ Infec Dis (in press)

58. Auger I. Incubation periods for paediatric AIDS patients. Nature 1988 336: $575-577$

59. Gougeon ML, Olivier S, Garcia D et al. Mise en evidence d'un processus d'engagement vers la mort cellulaire par apoptose dans les lympocytes de patients infecte par le VIH. C R Acad Sci Paris. Ser III Sc Vie 1991; 312 529-540.

60. Ameisen JC, Capron A. Cell dysfunction and depletion in AIDS: the programmed cell death hypothesis. Immunol Today 1991; 12: 102-106.

61. Clerici M, Sarin A, Coffman RL et al. Type 1/type 2 cytokine modulation of $\mathrm{T}$ cell programmed cell death as a model for HIV pathogenesis. Proc Nat Acad Sci (USA) 1994; 91: 11811-11815.

62. Asjo B, Manson-Morferldt L, Albert J et al. Replicative capacity of human immunodeficiency virus from patients with varying severity of HIV infection. Lancet 1986; ii: 660-662.

63. Tersmette M, De Goede REY, Al BJM et al. Differential syncytium-inducing capacity of human immunodeficiency virus isolates: frequent detection of syncytium-inducing isolates in patients with acquired immunodeficiency syndrome (AIDS) and AIDS-related complex. $J$ Virol 1988; 62: 2026-2032

64. Tersmette M, Lange JMA, De Goede REY et al. Association between biological properties of human immunodeficiency virus variants and risk for AIDS and AIDS mortality. Lancet 1989; i: 983-985.

65. Fenyo EV, Albert J, Asjo B. Replicative capacity, cytopathic effect and cell tropism of HIV. AIDS 1989; 3 (suppl. S-1): 5-12.

66. Schuitemaker, $\mathrm{H}$ et al. Biological phenotype of human immunodeficiency virus type 1 clones at different stages of infection: progression of disease is associated with a shift from monocytotropic to T-cell-tropic virus populations. J Virol 1992; 66: 1354-1360.

67. Koot $\mathrm{M}$ et al. Prognostic value of HIV-1 syncytium-inducing phenotype for rate of CD4 + cell depletion and progression to AIDS. Ann Intern Med 1993; 118: 681-688.

68. Anonymous. Immune based therapies for HIV infection. Meeting report Clinical Immunology Spectrum 1993; 6: 18-21.

Received 26 May 1995;

accepted 29 May 1995 


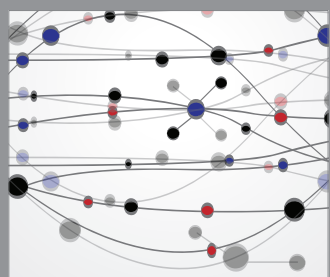

The Scientific World Journal
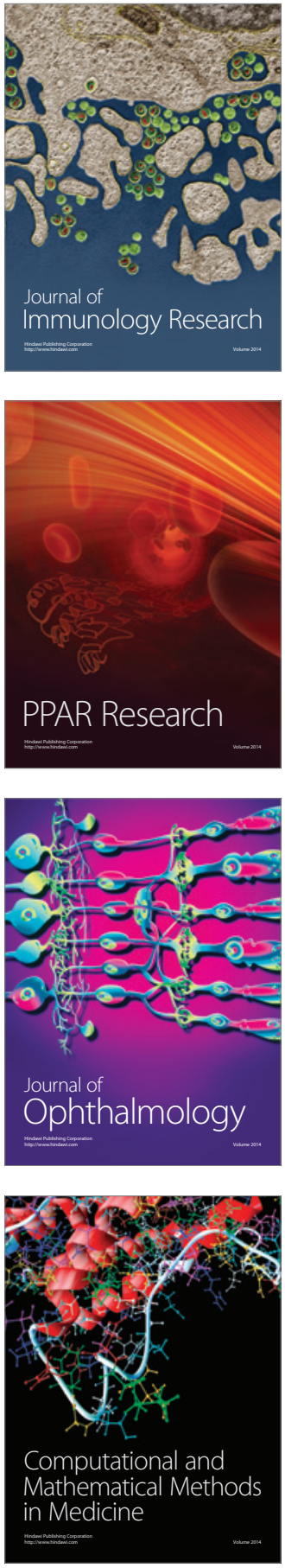

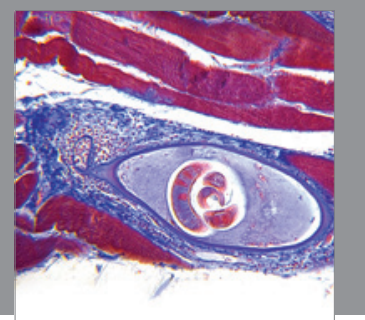

Gastroenterology

Research and Practice
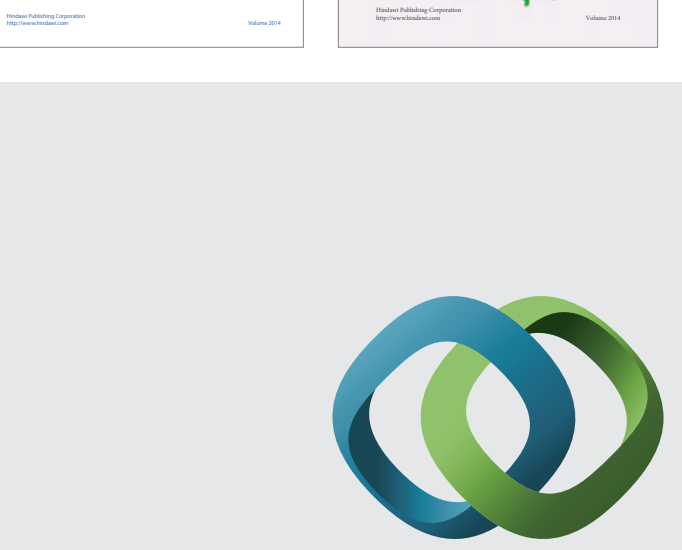

\section{Hindawi}

Submit your manuscripts at

http://www.hindawi.com
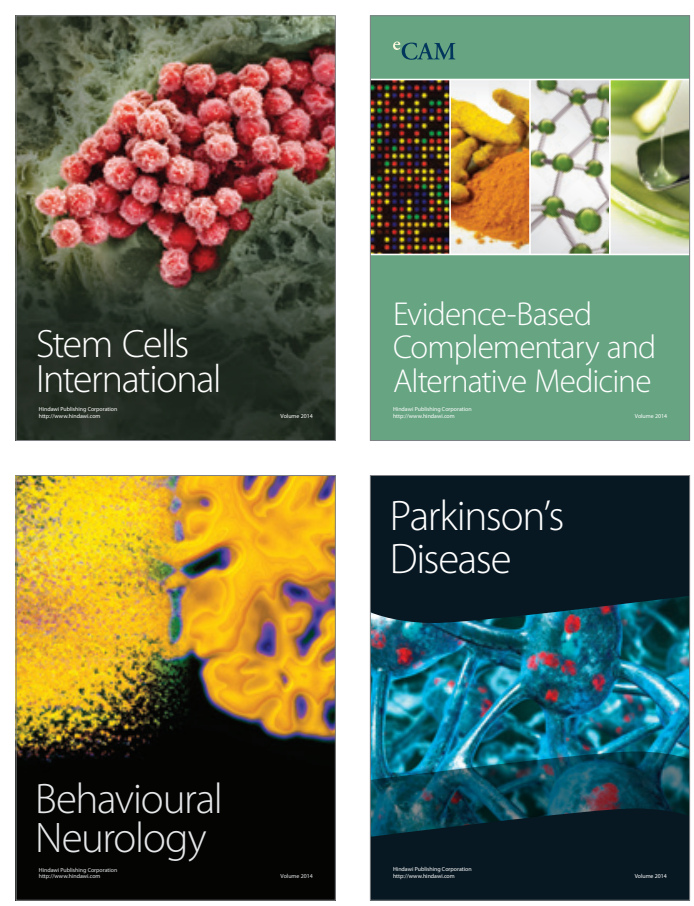

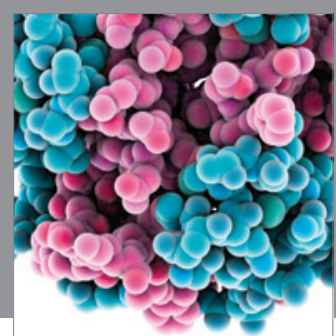

Journal of
Diabetes Research

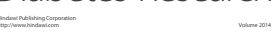

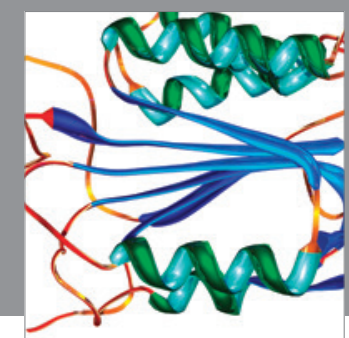

Disease Markers
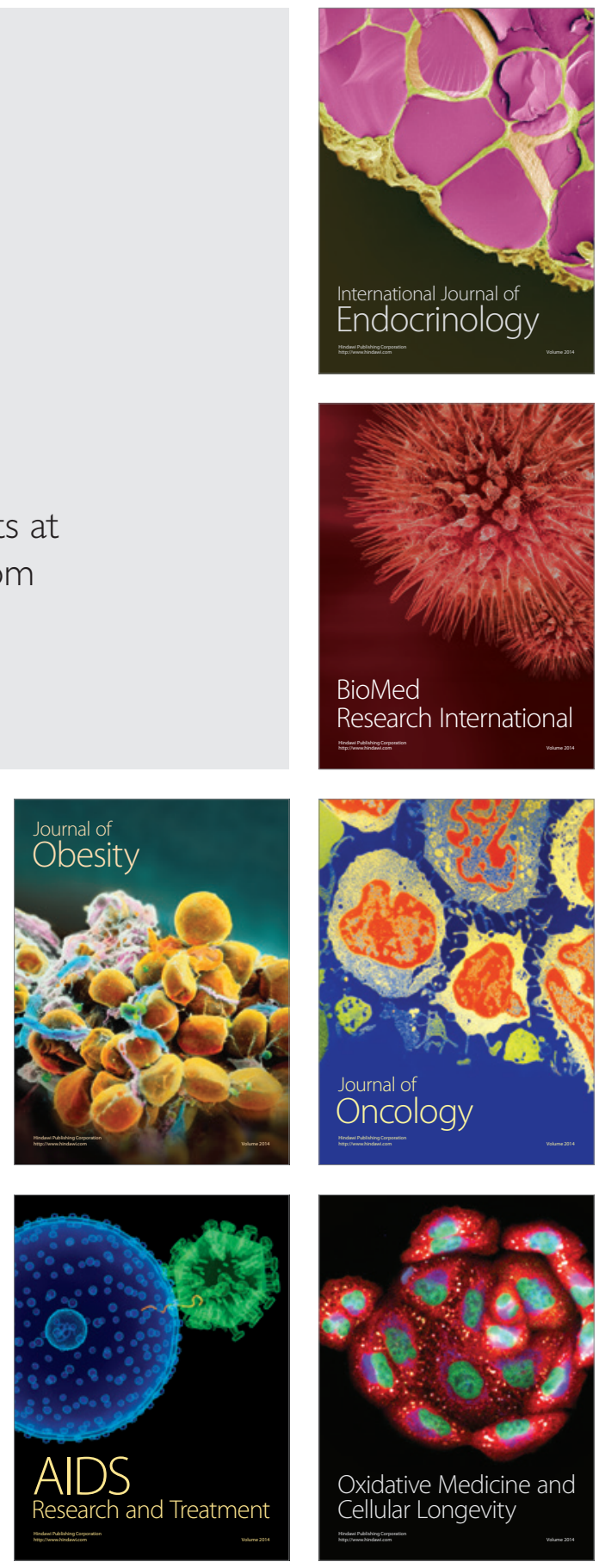